\title{
Misorientation distribution of high angle boundaries formed by grain fragmentation: EBSD-based characterization and analysis performed on heavily deformed iron
}

\author{
N. Yu. Zolotorevsky ${ }^{1, \dagger}$, V. V. Rybin ${ }^{1}$, A. N. Matvienko ${ }^{1}$, E. A. Ushanova ${ }^{2}$, S. N. Sergeev ${ }^{3}$ \\ †zolotorevsky@phmf.spbstu.ru \\ ${ }^{1}$ Institute of Applied Mathematics and Mechanics, Peter the Great Polytechnic University, \\ 29 Politekhnicheskaya str., St-Petersburg, 195251, Russia \\ ${ }^{2}$ Central Research Institute of Structural Materials “Prometey”, 49 Shpalernaya str., St-Petersburg, 191015, Russia \\ ${ }^{3}$ Institute for Metals Superplasticity Problems RAS, 39 Khalturina str., Ufa, 450001, Russia
}

When studying crystal lattice fragmentation during plastic deformation of metals, it is of great importance to have qualitative characteristics of high angle deformation-induced boundaries since their formation and evolution control grain refinement. It is challenging, however, to separate the contribution of deformation-induced boundaries (DIBs) to overall misorientation distribution from the contribution of original grain boundaries, particularly when total lengths of high-angle deformationinduced and original grain boundaries are comparable. The present study suggests a method making this separation possible basing on electron backscattering diffraction (EBSD) and uses the method to characterize the evolution of DIB misorientations in polycrystalline iron deformed under various conditions. The method provides a reasonable accuracy up to the strain of about 2 in the case of uniaxial compression and up to the strain of 5 in the case of biaxial forging. It has been shown that the character of evolution of DIBs in iron changes weakly when the deformation temperature increases from the room one to $400^{\circ} \mathrm{C}$. At the same time, the evolution differs significantly in iron deformed by uniaxial compression and biaxial forging. In all cases considered in the present study the misorientation distribution of DIBs can be represented as a superposition of three partial distributions. The first two partial distributions correlate with those obtained earlier in transmission electron microscopic studies. The third one suggested in the present study describes the highest-angle part of misorientation distribution of DIBs. Each partial distribution evolves according to its own law in the process of deformation.

Keywords: plastic deformation, microstructure, grain boundaries, misorientations, EBSD.

УДК: 539.5

Распределение разориентировок на большеугловых границах деформационного происхождения: определение и анализ на базе данных по дифракции обратно рассеянных электронов на примере железа, подвергнутого большим деформациям

\author{
Золоторевский Н. Ю. ${ }^{1, \dagger}$, Рыбин В. В. ${ }^{1}$, Матвиенко А. Н. ${ }^{1}$, Ушанова Е. А. ${ }^{2}$, Сергеев С. Н. ${ }^{3}$ \\ ${ }^{1}$ Институт прикладной математики и механики, Политехнический университет Петра Великого, \\ ул. Политехническая 29, Санкт-Петербург, 195251, Россия \\ ${ }^{2}$ Центральный научно-исследовательский институт конструкционных материалов «Прометей», \\ ул. Шпалерная 49, Санкт-Петербург, 191015, Россия \\ ${ }^{3}$ Институт проблем сверхпластичности металлов РАН, ул. Халтурина 39, Уфа, 450001, Россия
}

Для изучения фрагментации кристаллической решетки металлов в процессе больших деформаций важно иметь количественные данные о большеугловых границах деформационного происхождения, поскольку фрагментация контролируется их формированием и эволюцией. Однако проблемой является разделение вкладов от границ деформационного происхождения и исходных границ зерен в общее распределение разориентировок, в особенности, если суммарные протяженности большеугловых границ деформационного происхождения и исходных границ зерен сопоставимы. В настоящей работе предложен метод, позволяющий осуществить такое разделение на базе данных, полученных с помощью дифракции обратно рассеянных электронов (EBSD) в поликристаллическом железе, 
деформированном в разных условиях. Предложенный метод дает приемлемую точность при деформации примерно до 2 в случае одноосного сжатия и до 5 в случае двухосной ковки. Показано, что при сжатии железа повышение температуры деформации от комнатной до $400^{\circ} \mathrm{C}$ слабо влияет на характер эволюции границ деформационного происхождения. В то же время, эволюция границ деформационного происхождения существенно различается в железе, деформированном сжатием и двухосной ковкой. Во всех рассмотренных случаях распределение разориентаций на границах деформационного происхождения можно представить, как суперпозицию трех частных распределений. Первые два распределения коррелируют с распределениями, полученными ранее с помощью просвечивающей электронной микроскопии. Третье распределение, предложенное в настоящей работе, описывает большеугловую часть распределения разориентировок на границах деформационного происхождения. В процессе деформации каждое из трех частных распределений развивается по своим законам.

Ключевые слова: пластическая деформация, микроструктура, границы зерен, разориентировки, ДОИ.

\section{Introduction}

Formation of ultra-fine grain structures in metallic materials by plastic deformation is controlled by fragmentation, i.e. the subdivision of original grains into microscopic volumes, misorientations of which gradually increase while the sizes decrease with increasing strain [1]. A common character of this phenomenon was shown by numerous investigators, though morphological and crystallographic characteristics of the fragmented microstructure may depend on the material and deformation conditions [1-11].

The process of fragmentation is associated with the emergence and development of deformation-induced boundaries (DIBs). Initially the dislocation cell boundaries appear, next fragment boundaries form, which have higher misorientations as well as denser and straighter configurations [1]. At equivalent strains up to about 1 , the cell and fragment boundaries are characterized by misorientation angle distributions, which retain their shape with increase in strain when scaled by the average angles [12]. However, with a further increase in strain, the scaling of misorientation angle distribution of the fragments breaks down due to the appearance of multiple high-angle DIBs [1,4-5]. It should be noted that the above mentioned studies of DIB misorientation distributions were based on the TEM analysis. At the same time, EBSD technique, although not allowing one to visually distinguish boundaries of different types, provides much better statistics of misorientations than TEM does [13-14].

The high-angle DIBs are of a particular interest since their formation alone controls the formation of ultra-fine grain structures. It is challenging, however, to separate the contributions of high angle DIBs from those of original grain boundaries (OGBs) to the overall misorientation distribution when using EBSD, particularly, at mediate strains of about 1 to 3 , when total lengths of these boundaries are comparable. The EBSD-based method suggested in the present study makes it possible to solve the problem. The method will be briefly described and then used to analyze the distribution of misorientation angles of DIBs in iron.

\section{Experiment}

Polycrystalline Armco-iron was used for the study. The initial mean grain size determined by the linear interception method was about $26 \mu \mathrm{m}$. Uniaxial compression (UC) tests were carried out in the laboratory system Gleeble-3800 at room temperature (RT) and $400^{\circ} \mathrm{C}$ with a strain rate of
$10 \mathrm{~s}^{-1}$. The examined areas were located at an approximately half-height of the upset sample. At that, the strain $\varepsilon$ within the equatorial plane of the specimens was evaluated with regard to the barreling effect. Biaxial forging (BF), i.e. the cyclic compression in two mutually orthogonal directions, was applied by using MAXStrain unit of the Gleeble at RT with the same strain rate and with a true strain of 0.5 per pass. In this case, the examined areas were located at the central part of the specimens.

The EBSD measurements were performed with scanning microscopes Quanta 2003D FEG and TESCAN MIRA 3LMH. Orientation mapping was conducted with the scanning steps of $100 \mathrm{~nm}$ for $\varepsilon=1$ and $50 \mathrm{~nm}$ for larger strains. The areas of the mapped regions varied from about $50 \times 50 \mu \mathrm{m}$ to $60 \times 60 \mu \mathrm{m}$. To determine misorientations, processing of the orientation data and crystallographic analyses was carried out with the help of MTEX software [15] with a threshold angle of $2^{\circ}$.

\section{Method of separating DIBs contribution to overall misorientation distribution}

The idea behind the method is based on the observations, according to which misorientation does not increase uniformly over the length of a DIB in the process of deformation. Instead, the misorientation angle can vary from tens of degrees at one segment of the boundary to the values as low as about $1^{\circ}$ at the other segment [1]. On the contrary, the majority of OGBs retain a high angle, although non-uniform [16], misorientation over their total length. This difference of DIBs and OGBs alone provides a basis for separation of boundaries of these two types.

First, let us consider iron compressed at RT to $\varepsilon=1$. The EBSD map in Fig. 1a shows multiple DIBs developed inside original grains, where the gradations of gray indicate the misorientation angle. Our first purpose is to obtain a map where only OGBs remain. Since the majority of DIBs are low angle ones, at least over a part of their length, they can be removed from the map with MTEX function of "grain detection", which only keeps boundaries with misorientation angles exceeding the specified value $\theta_{\text {min }}$ over their total length $\left(\theta_{\min }\right.$ of $15^{\circ}$ is used in the first approximation, yet the tuning of the value may be required). Although most of DIBs disappear from the map after this procedure, some minor "grains", which are supposed to be deformation-induced fragments, still remain. In order to remove them too, MTEX option for removing grains that occupy the area smaller than 
a specified one, $A_{\text {min }}$, can be used ${ }^{1}$. The result obtained with $\theta_{\text {min }}=16^{\circ}$ and $A_{\text {min }}=20 \mu \mathrm{m}^{2}$ is shown in Fig. 1b. Based on visual perception and with regard to the mean grain size of $26 \mu \mathrm{m}$, mainly OGBs are present on this map. For the initial map (Fig. 1a) and the final map (Fig. 1b), the overall and OGB misorientation distributions are determined, respectively, in terms of the boundary length. Then, by subtracting the second distribution from the first one, the required DIB distribution, shown by a full line in Fig. 1c, is determined.

The other example is iron compressed at RT to $\varepsilon=1.6$. As it could be expected, the increase of strain complicates the separation of OGBs due to the enhanced fragmentation. The fact that both boundaries of the large fragments and OGBs are similarly extended perpendicular to the compression axis involves difficulties as well. As a result, basing on the morphology of the grains presented in Fig. 1e (the map was obtained with $\theta_{\min }=16^{\circ}$ and $A_{\text {min }}=10 \mu \mathrm{m}^{2}$ ), it cannot be asserted with high confidence that we deal with the OGB network. To validate the result, it is useful to compare a mean transverse grain size measured along the compression axis on this map to a theoretical transverse grain size calculated on assumption that the grain shape follows the sample shape during compression as $D_{\text {th }}=D_{0} e^{-\varepsilon}$, where $D_{0}$ is an average grain size in the undeformed material. With $D_{0}=26 \mu \mathrm{m}$ and

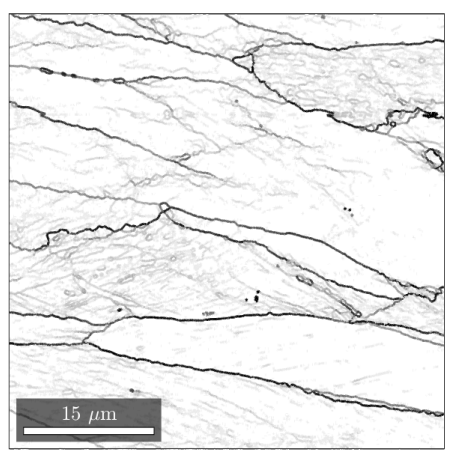

a

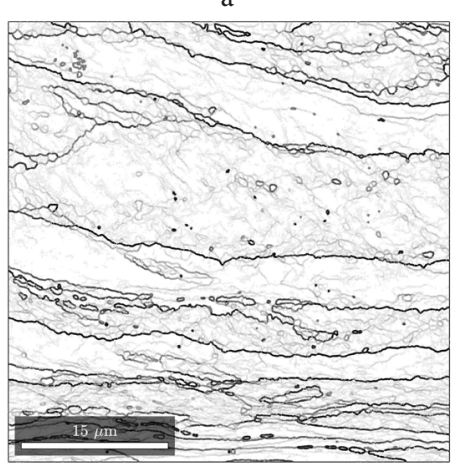

d

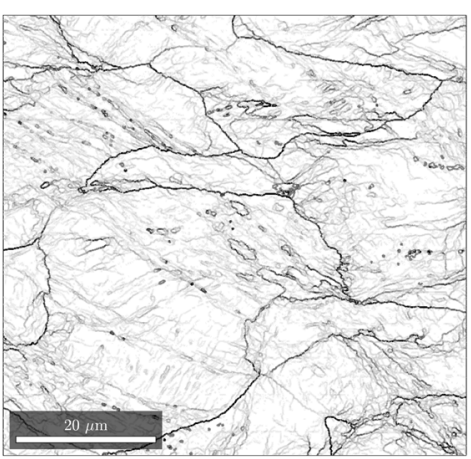

$\mathrm{g}$

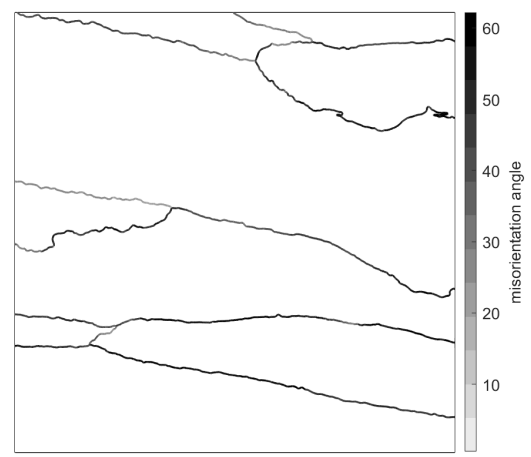

$\mathrm{b}$
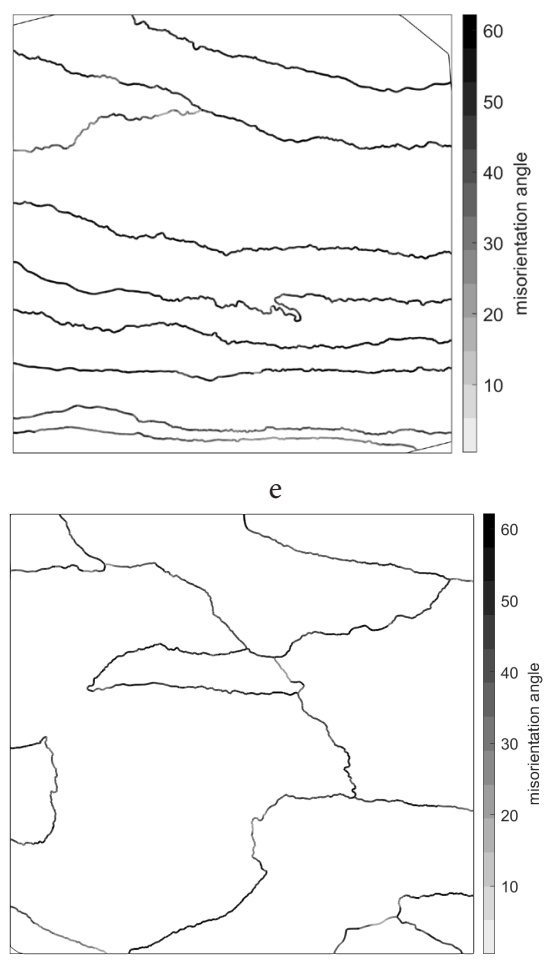

$\mathrm{h}$

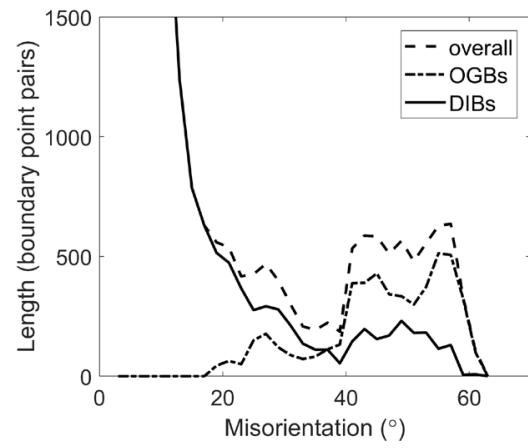

c

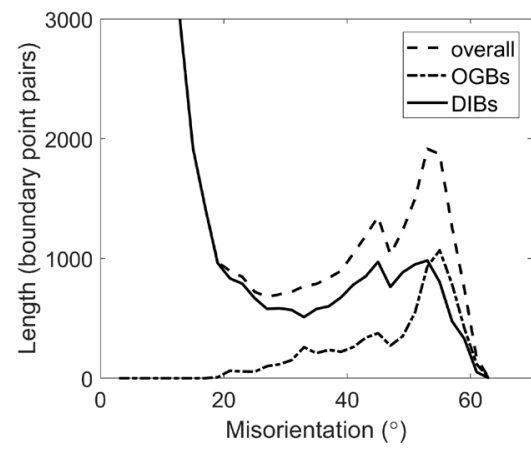

f

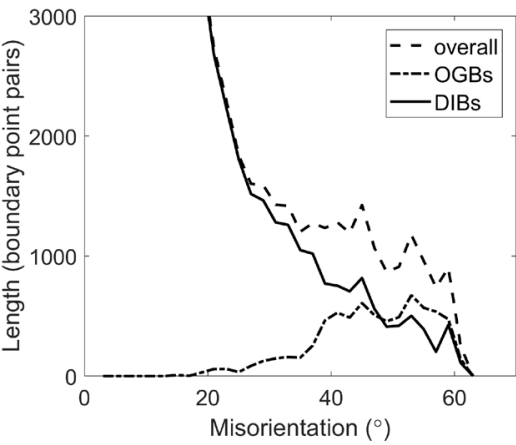

i

Fig. 1. EBSD boundary maps and misorientation angle histograms ${ }^{2}$ illustrating the procedure used to determine a DIB misorientation distribution: iron, UC, RT, $\varepsilon=1$ (a,b,c); iron, UC, RT, $\varepsilon=1.6$ (d,e,f); iron, BF, $\varepsilon=5$ (g,h,i). The shades of gray indicate misorientation angles as shown in the shading key.

1 The optimal value of $A_{\min }$ is selected taking into account the morphology and sizes of the "grains" obtained on the map. The author's experience in using this procedure shows that this value rather depends on fragmentation peculiarities (hence, on materials, conditions of deformation and the level of strain) than on the grain size of the initial microstructure.

2 Here and further, the misorientation angle histograms obtained with the bin width of $2^{\circ}$ are represented using line plots for simplicity of their comparing. 
$\varepsilon=1.6$, the value of $5.2 \mu \mathrm{m}$ is obtained for $D_{\text {th }}$. The measured mean size, which is close to $5 \mu \mathrm{m}$, agrees quite well with this estimate.

Although separation of OGBs in the case of compression to $\varepsilon=1.6$ was found to be reasonable, its accuracy is expected to deteriorate considerably with a further increase in strain. At the same time, it turned out that this procedure remains applicable to much larger strains when using BF. In the latter case the applicability of the method seems to be provided by maintenance of the equiaxed grain shape and diminished formation of high-angle boundaries. Figs. 1g, h show the microstructure of the sample deformed by BF to $\varepsilon=5$ and the result of OGBs selection $\left(\theta_{\min }=13^{\circ}\right.$ and $\left.A_{\min }=20 \mu \mathrm{m}^{2}\right)$, respectively. Although some smaller "grains" in Fig. 1h may be deformation-induced fragments, the contribution of ambiguous boundaries is estimated to be about $10 \%$, which characterizes the accuracy of the results presented in Fig. 1i.

\section{Results and discussion}

The method described above was employed to compare the evolution of DIBs in different deformation conditions. Here, it is reasonable to represent DIB misorientation distributions in terms of a boundary length instead of the common representation in terms of frequencies. For the given sample, we initially have the boundary length expressed in numbers of boundary point pairs (Fig. 1). However, since the orientation mapping was conducted with different scanning steps and/or the orientation maps have different areas, the boundary length per unit area should be considered in order to ensure that the misorientation distributions found for different samples are comparable. It should be noted that the length per unit area of the boundaries with misorientation angles larger than a certain value $\theta^{\prime}, L\left(\theta>\theta^{\prime}\right)$, is inversely proportional to the mean linear intercept length, $d\left(\theta>\theta^{\prime}\right)$, measured for these boundaries [17]. Thus, the data on the boundary length distribution can not only be used to evaluate relative fractions of boundaries with different misorientation angles but to evaluate structure refinement as well.

Fig. 2 demonstrates the evolution of DIBs in iron under $\mathrm{UC}$ and $\mathrm{BF}$ depending on strain and temperature. It is seen that the variation of deformation temperature has a weak, if any, effect on the fragmentation during UC. At both temperatures, the length of the low angle boundaries increases with further strain but the shape of the low angle peak remains the same. The high angle part of the distributions in case of UC changes more significantly: a pronounced high angle peak appears at strains of 1.6 and 1.8. In case of BF, the misorientation distribution is similar to the distribution formed after UC at $\varepsilon=1$. However, the further evolution of DIBs under BF differs significantly: only a minor formation of high angle boundaries occurs with increasing strain up to 5 . Note that this result agrees qualitatively with those obtained for lowcarbon and microalloyed steels deformed by BF [18-19]. At the same time, no final conclusion should be drawn about the potential of bi-axial forging as the structure refinement technique for iron. Further studies based on much larger mapping areas are needed.

The DIB misorientation distributions, which have been obtained and compared above, can be then evaluated using a

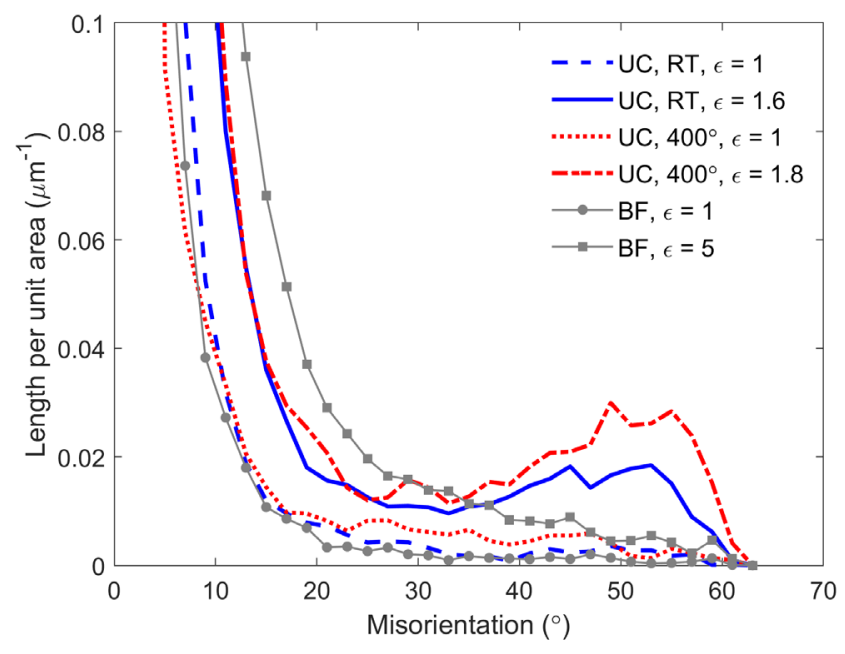

Fig.2. DIB misorientation angle distributions represented in terms of boundary length for iron deformed under various conditions.

more sophisticated approach by means of their representation as a sum of partial distributions, each corresponding to the boundaries of a certain type [20-21]. In order to represent the low angle part of the distribution, the results obtained in TEM studies of Risø school [12] should be taken into account. The studies have shown that, if misorientation angle distributions $f(\theta)$ are plotted separately for (A) cell boundaries termed incidental dislocation boundaries (IDBs) in [12] and (B) fragment boundaries termed geometrically necessary boundaries (GNBs), they can be well approximated by gamma distributions which turn out to be self-similar when using the average misorientation angle $\theta_{a v}$ as a scaling parameter: $g(x)=a^{a} / \Gamma(a) x^{a-1} \exp (-a x)$, where $x=\theta / \theta_{a v}$ and $\Gamma(a)$ is the gamma function evaluated at argument $a ; a=3$ for IDBs and $a=2.5$ for GNBs. However, the GNB distribution does not scale at strains larger than $\varepsilon \sim 1$ due to the formation of high angle DIBs that create an additional peak [1,4-8]. Taking this into account, it is reasonable to consider three partial distributions: $f_{1}$ and $f_{2}$ corresponding presumably to the IDB and GNB distributions, respectively, and $f_{3}$ accounting for the high angle boundaries which go beyond the scope of $f_{2}$. Therefore, the first two distributions are determined as $f_{1}(x)=g\left(x=\theta / \theta_{1} ; a=3\right), f_{2}(x)=g\left(x=\theta / \theta_{2} ; a=2.5\right)$, where $g(x)$ is defined above; $\theta_{1}$ and $\theta_{2}$ are average angles for these distributions. Concerning the third distribution, let us suppose that a fragment boundary passes on from $f_{2}$ to $f_{3}$ when its misorientation begins to increase rapidly after reaching critical angle $\theta_{c}$. It can be expressed as $\theta=\theta_{c}+\delta \theta$, where $\theta_{c}$ is a constant $\left(\theta_{c}=12^{\circ}\right.$, which approximately fits to all the data considered, was used in the modeling) and the increment $\delta \theta$ is described as $f_{3}(x)=g\left(x=\delta \theta / \delta \theta_{3} ; a=2.5\right)$. The parameter $a$ was taken here as in case of the partial distribution $f_{2}$ for simplicity.

Concerning the distribution $f_{3}$, it should be taken into account that angles $\theta$ can exceed the maximum disorientation angle (the disorientation is defined as a minimum angle relationship between crystallites with regard to crystal lattice symmetry [22]). In such a case a crystallographic texture must be considered as long as the disorientation angle distribution depends on the occurrence of a preferred rotation axis [23]. 
The latter is the case for UC of iron, since then the twocomponent $<111>-<100>$ fiber texture develops [24]. Taking into account that these components are related by rotation about $\langle 110\rangle$ axis, the disorientation angle distribution $f_{3}$ was generated assuming that angles $\theta$ are distributed as stated above, while rotation axes concentrate near $\langle 110\rangle$ and their angular deviation from $<110>$ obeys the Gaussian distribution (the standard deviation was taken as $15^{\circ}$ in the modeling).

The parameters of the partial distributions were estimated from the best fit to experimental data. Fig. 3 demonstrates some examples of the analysis. Note that, according to TEM [5,8], IDB misorientations increase so slowly with deformation that the average angle $\theta_{1}$ reaches the level of $\sim 2^{\circ}$ only at $\varepsilon>1$. Thus, when using a threshold angle of $2^{\circ}$, about one half of IDBs is ignored in the EBSD analysis. As a result, estimations of $\theta_{1}$ based on these data are expected to be very rough: angles $\theta_{1}$ belonging to the range $\sim 1.5-2.5^{\circ}$ provide equally good fit to the experiment. At the same time, the present estimation of $\theta_{2}$ appears to be representative.
The agreement of the estimates of $\theta_{1}$ and $\theta_{2}$ for the samples deformed to $\varepsilon=1$ (Figs. 3a,b) with TEM results on IDBs and GNBs $[5,8,12]$ confirms that representation of the lower angle part of DIB distribution as a sum of two partial distributions corresponding to IDBs and GNBs is plausible.

With increasing strain, only a slight increase of $\theta_{2}$ occurs, while a relative contribution of $f_{2}$ remains approximately constant or becomes smaller (Figs. $3 \mathrm{c}, \mathrm{d}$ ). At the same time, the contribution of $f_{3}$ as well as the value of $\theta_{3}$ increases considerably, especially in the case of UC. Therefore, the most significant feature of the evolution of DIBs at strains $\varepsilon>1$ is an accelerated development of partial distribution $f_{3}$.

As is seen in Fig. 3, the suitability of gamma distribution for $f_{3}$ distribution is not as apparent as for $f_{2}$. Note, however, that in the cases of $\varepsilon=1$ the discrepancy between the predicted and experimental distributions might appear since only rare DIBs with misorientations above $20^{\circ}$ occur at this strain, which increases a statistical error. For larger strains experimental distributions are more statistically representative in the high angle range and, thus, a better
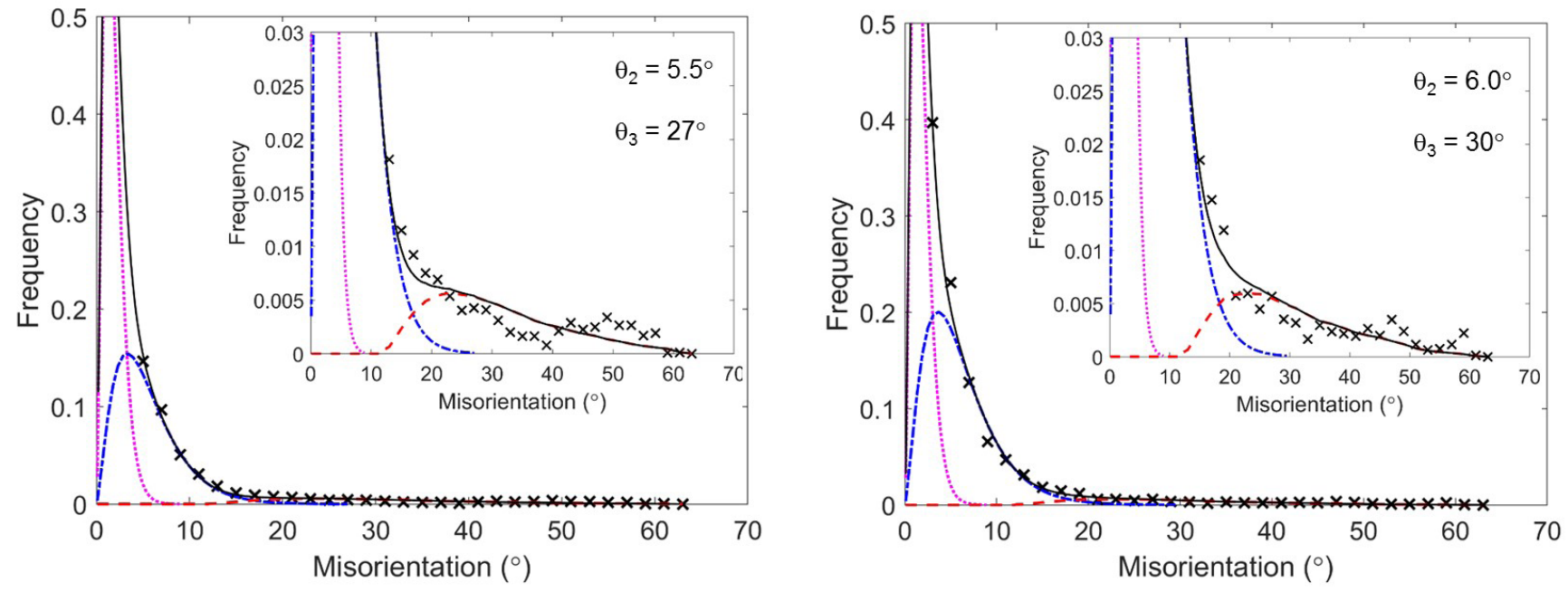

a

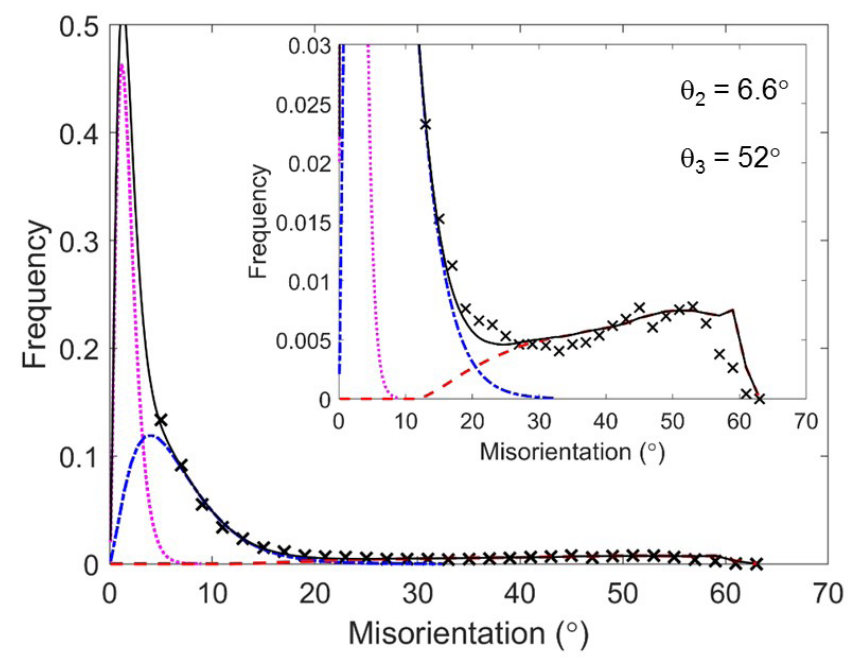

$\mathrm{b}$

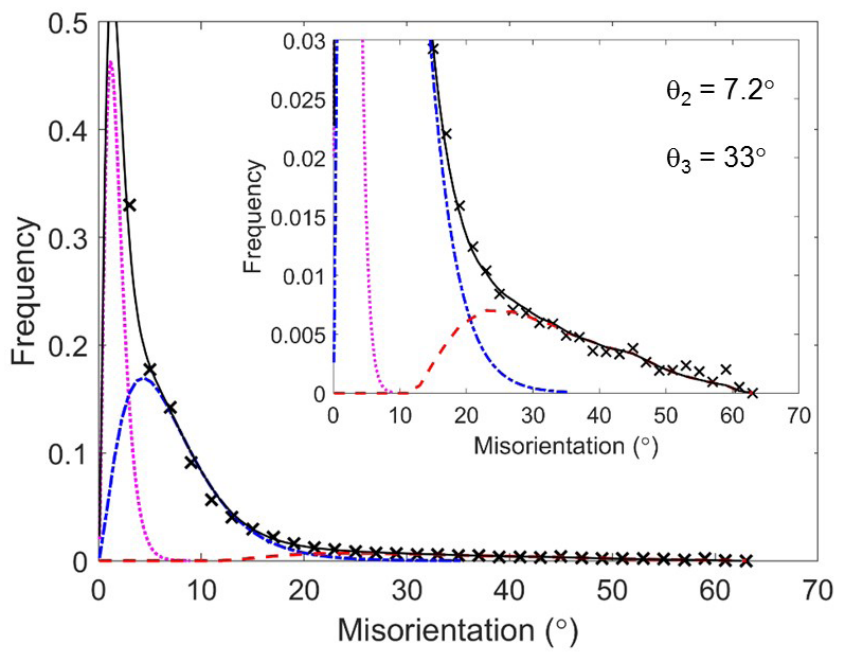

d

Fig. 3. DIB misorientation distributions (crosses) in iron deformed at room temperature to $\varepsilon=1$ by UC (a), $\varepsilon=1$ by BF (b), $\varepsilon=1.6$ by UC (c) and $\varepsilon=5$ by $\mathrm{BF}(\mathrm{d})$, with their representations as a superposition of partial distributions $f_{1}$ (dot lines), $f_{2}$ (dash-dot lines) and $f_{3}$ (dash lines). Full lines show the sum of the partial distributions. The magnified images of high angle parts of the distributions are displayed separately. Average angles $\theta_{2}$ and $\theta_{3}$ of partial distributions $f_{2}$ and $f_{3}$ estimated from the best fit to the experimental data are given on the plots. 
agreement may be expected. Indeed, a good description of the high angle part of distribution has been obtained for $\mathrm{BF}$ to $\varepsilon=5$, when a pronounced texture was absent. For UC to $\varepsilon=1.6$ the description seems to also be reasonable, whereas the deviation taking place in this case may be due to a rough approximation of the texture effect. Anyway, it should be noted that the choice of gamma distribution, although plausible, is purely empirical [25]: it has no significance concerning our understanding of the fragmentation mechanism. Further investigations are required for an adequate theoretical description of the evolution of high angle DIBs.

\section{Summary}

The method of separating a contribution of DIBs to the overall misorientation distribution suggested and described in the present study provides an acceptable accuracy within a certain range of strains and deformation modes. It has been shown that the character of DIBs evolution in iron changes weakly when increasing the deformation temperature from room one to $400^{\circ} \mathrm{C}$. At the same time, the evolution differs significantly in iron deformed by UC or BF. In both cases the DIB misorientation distribution can be represented as a superposition of three partial distributions. The following features of this representation should be noted:

1. In the low angle range, the DIB misorientation angle distribution can be described as a sum of distributions $f_{1}$ and $f_{2}$, the parameters of which correlate with the parameters of IDB and GNB misorientation distributions determined previously by TEM.

2. The high angle DIBs, the misorientations of which fall beyond the range of the first two partial distributions, are described using distribution $f_{3}$. Its contribution appears to be noticeable at the strain $\sim 1$ and then gradually increases with further deformation.

\section{References}

1. V.V. Rybin. Large plastic deformations and fracture of metals. Moskva, Metallurgiya (1986) 224 p. (in Russian) [В.В. Рыбин. Большие пластические деформации и разрушение металлов. Москва, Металлургия (1986) $224 \mathrm{c.}$.]

2. T. G. Langdon. Acta Mater. 61, 7035 (2013).

3. J. Gil Sevillano, P. Van Houte, E. Aernoudt. Progr. Mater.
Sci. 25, 69 (1980)

4. D. A. Hughes, N. Hansen. Acta Mater. 45, 3871 (1997).

5. D. A. Hughes, N. Hansen. Acta Mater. 48, 2985 (2000).

6. E.V. Nesterova, V.V. Rybin, N. Yu. Zolotorevsky. Phys. Met. Metallogr. 89(1), 42 (2000).

7. B. L. Li, A. Godfrey, Q.C. Meng, Q. Liu, N. Hansen. Acta Materialia. 52, 1069 (2004).

8. J. Kawałko et al. Mater. Characterization. 141, 19 (2018).

9. N.Yu. Zolotorevsky, V.V. Rybin. Fragmentation and texture formation in heavily deformed metallic materials. Saint-Petersburg, Polytechnic University (2014) 208 p. (in Russian) [Н.Ю. Золоторевский, В.В. Рыбин. Фрагментация и текстурообразование при деформации металлических материалов. Санкт-Петербург, Изд-во Политехнического университета (2014) 208 с.]

10. V.V. Rybin, N.Yu. Zolotorevskii, E. A. Ushanova. Technical Physics 59(12), 1819 (2014).

11. Z. Yanushkevich, A. Belyakov, R. Kaibyshev. Acta Mater. 82, 244 (2015).

12. D. A. Hughes, Q. Liu, D.C. Chrzan, N. Hansen. Acta Mater. 45, 105 (1997).

13. P. J. Hurley, F. J. Humphreys. J. Microsc. 205, 218 (2002).

14. O. V. Mishin, A. Godfrey, L. Östensson. Metal. Mater. Trans. A. 37A, 489 (2006).

15. F. Bachmann, R. Hielscher, H. Schaeben. Ultramicroscopy. 111, 1720 (2011).

16. G. Salishchev, S. Mironov, S. Zherebtsov, A. Belyakov. Mater. Characterization. 61, 732 (2010).

17. S. A. Saltykov. Stereometric metallography, $2^{\text {nd }}$ ed. Moscow, Metallurgizdat (1958) 270 p. (in Russian) [C. А. Салтыков. Стереометрическая металлография. Москва, Металлургия (1976) 270 с.]

18. K. Muszka, S. Dymek, J. Majta, P. Hodgson. Archives of Metallurgy and Materials. 55, 641 (2010).

19. D. S. Svyetlichnyy, K. Muszka, J. Majta. Computational Materials Science. 102, 159 (2015).

20. V.V. Rybin, N.Yu. Zolotorevsky, E. A. Ushanova. Phys. Met. Metallogr. 116, 730 (2015).

21. N. Yu. Zolotorevsky, V. V. Rybin, E. A. Ushanova, A Mater. Characterization. 122, 70 (2016).

22. J. K. Mackenzie. Biometrika. 45, 229 (1958).

23. V.Yu. Gertsman, A.P. Zhilyaev, A.I. Pshenichnyuk, R.Z. Valiev. Acta Metal. Mater. 40, 1433 (1992).

24. G. Wassermann, and J. Grewen. Texturen Metallischer Werkstoffe. Springer-Verlag, Berlin (1962) 808 p.

25. W. Pantleon. Mater. Sci. and Eng. A. 319-321, 211 (2001). 